\title{
Isolation and characterization of minipig perivascular stem cells for bone tissue engineering
}

\author{
ZHEN CUI $^{1}$, CHENSHUANG LI ${ }^{1}$, NAN JIANG ${ }^{2}$, CI ZHANG ${ }^{1}$, \\ YIRAN WANG $^{1}$, HONGYUN GAO $^{3}$ and YANHENG ZHOU ${ }^{1}$ \\ ${ }^{1}$ Department of Orthodontics; ${ }^{2}$ Central Laboratory, Peking University School of Stomatology, Beijing 100081; \\ ${ }^{3}$ Surgical Operating Room, Beijing Huangsi Plastic Surgery Hospital, Beijing 100020, P.R. China
}

Received July 13, 2017; Accepted October 25, 2017

DOI: $10.3892 / \mathrm{mmr} .2018 .9410$

\begin{abstract}
Human subcutaneous adipose tissue has been recognized as a rich source of tissue resident mesenchymal stem/stromal cells (MSC) in recent years. The current study was designed to sort the minipig (mp) perivascular stem cells (PSCs) and investigate the osteogenic potential. Purification of human PSCs was achieved via fluorescence-activated cell sorting (FACS) from human liposuction samples [cluster of differentiation (CD) $45^{-} \mathrm{CD} 34^{-} \mathrm{CD} 146^{+}$perithelial cells and $\mathrm{CD} 45^{-} \mathrm{CD} 34^{+} \mathrm{CD} 146^{-}$adventitial cells]. Subsequently, PSCs were isolated from mp adipose tissue samples $(n=9)$, characterized and, using purified mpPSCs (obtained by FACS, which is used in human PSC purification), the mpPSC osteogenic and adipogenic potential was evaluated by Alizarin Red S and Oil Red O staining in vitro, respectively. The cell morphometry was observed following cell isolation and culture, and hematoxylin and eosin staining was performed to identify the fat tissue structure and vascular distribution. Osteogenic and adipogenic differentiation-associated gene expression levels were analyzed by reverse transcription-quantitative polymerase chain reaction. The results demonstrated that the same antigens used for human PSC identification and isolation were working in $\mathrm{mp}$ tissue (CD45, CD146 and CD34). The two cell groups: $\mathrm{CD} 45^{-\mathrm{CD}} 34^{-} \mathrm{CD} 146^{+}$pericytes

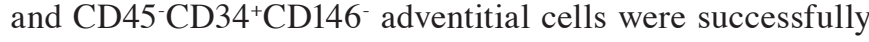
isolated from the subcutaneous fat in the posterior neck of mps, mpPSCs accounted for $8.6 \%$ of the stromal vascular fraction (SVF) with $1.4 \%$ pericytes and $7.2 \%$ adventitial cells. mpPSCs demonstrated characteristics of MSCs, including cell surface marker expression, colony forming unit-fibroblast inclusion, and the stronger osteogenic and adipogenic differentiation potential than that of the non-selected vascular stromal
\end{abstract}

Correspondence to: Dr Yanheng Zhou, Department of Orthodontics, Peking University School of Stomatology, 22 Zhongguancun South Avenue, Beijing 100081, P.R. China E-mail: yanhengzhou@gmail.com

Key words: flow cytometry, perivascular stem cells, cluster of differentiation 146, cluster of differentiation 34, osteogenic potential cells. The mRNA expression levels of osteocalcin, collagen, type I, $\alpha 1$ and peroxisome proliferator-activated receptor- $\gamma$ in the mpPSCs group were significantly higher than those of the unsorted pSVF group $(\mathrm{P}<0.05)$. Thus, the current study successfully isolated and cultured $\mathrm{CD} 146^{+}$and $\mathrm{CD} 34^{+}$cell populations from $\mathrm{mp}$ tissues, characterized the cells' PSC-like phenotype and identified their distinctly osteogenic and adipogenic potential.

\section{Introduction}

Innovations are continuously being made in bone tissue engineering, from implanted material to bone substitutes, and subsequently autologous bone grafting (1-4), which avoids the issue of graft rejection; however, it has not solved the problem of limited endogenous supply, prolonged surgical duration and harvest complications (5-7). Cell sources, such as bone marrow mesenchymal stem cells and adipose-derived stem cells have generated significant interest for their tissue engineering potential $(8,9)$.

Perivascular stem cells (PSCs) are a homogeneous mesenchymal stem cell (MSC) population purified by fluorescence activated cell sorting (FACS). PSCs are cell populations that are comprised of pericytes [cluster of differentiation (CD) $\left.45^{-} \mathrm{CD} 34^{-} \mathrm{CD} 146^{+}\right)(10)$ and adventitial cells $\left(\mathrm{CD} 45^{-} \mathrm{CD} 34^{+} \mathrm{CD} 146^{\circ}\right)$, which are selected by fluorescence-activated cell sorting (FACS) (11). The histological localization is in blood vessels, and the two cell types have been reported to possess characteristics of mesenchymal stem cells (MSCs) (12-14). PSCs are the natural ancestors of MSCs, and are responsible for homeostasis and repair in vivo. Previous studies have indicated that purified PSCs have increased chondrogenic potential when compared with conventional MSCs derived in culture $(10,15)$. Lipoaspirate-derived human PSCs have demonstrated myogenic and angiogenic potential, and have exhibited a strong therapeutic effect in the treatment of rotator cuff tears (16). PSC xenografting demonstrated the osteogenic capability of this cell type in ectopic and orthotopic bone regeneration models (17). Additionally, a study indicated that osteoinductive growth factor Nel-like molecule 1 induced human (h) PSC osteogenesis (18). hPSCs may present as a promising cell source for future efforts in skeletal regenerative 
medicine. hPSCs provide a stem cell-based therapeutic modality that is readily approved by the United States Food and Drug Administration, with potentially increased safety, purity, identity, potency and efficacy (19).

PSCs are abundant in human white adipose tissue (20); thus, adipose tissue is an ideal MSC source, as it is dispensable and accessible with minimal morbidity. Therefore, in recent years, numerous studies describing the identification, isolation and characterization of PSCs from the adipose tissues of humans and animals have been performed $(9,11,20-22)$. However, at present, to the best of our knowledge, there are no studies on the purification and identification of PSCs in minipigs (mps). Therefore, it is hypothesized that there is a phenotype similar to that of the human body in mpPSCs. The findings may benefit cosmetic dentistry and facial cosmetic surgery fields, as the orthodontic tooth or craniofacial bone tissue repair are closely associated with the development of bone. The aim of the current study was to identify, isolate and characterize PSCs from $\mathrm{mp}$ adipose tissue samples $(n=9)$. Purification of mpPSCs by FACS (which is used in human PSC purification), and investigation of mpPSC osteogenic and adipogenic potential (using Alizarin Red S staining and Oil Red $\mathrm{O}$ staining in vitro, respectively) was performed, followed by observing the cell morphometry after cell isolation and culture. In addition, hematoxylin and eosin (H\&E) staining was conducted to identify the fat tissue structure and vascular distribution. Furthermore, osteogenic induction differentiation regulating genes, osteocalcin (OCN) and collagen, type I, $\alpha 1$ (COL1A1), and the adipogenesis-associated gene, peroxisome proliferator-activated receptor- $\gamma$ (PPARG) (23) were evaluated by reverse transcription-quantitative polymerase chain reaction (RT-qPCR).

\section{Materials and methods}

PSC identification, isolation and culture.hPSCs were provided by liposuction patients (anonymous) following surgery at the Beijing Huangsi Cosmetic Plastic Surgery Hospital (Beijing, China). The mp adipose tissue samples were obtained from 9 male, health-certified Guizhou mps (age, 10 months; mean weight, $37 \mathrm{~kg}$ ) from the Chinese Academy of Agricultural Sciences (Beijing, China). All protocols were approved by the Animal Use and Care Committee of Peking University (Beijing, China; permit no. LA2014216). Unless otherwise stated, the subcutaneous fat from the posterior neck of the mps was used.

In order to determine the minipig stromal vascular fraction (SVF) yield, H\&E staining was performed on tissue sections $\left(\sim 1 \mathrm{x} 1 \mathrm{x} 0.5 \mathrm{~cm}^{3}\right)$. The mp adipose tissue samples were snap frozen and cryosections were obtained at $-30^{\circ} \mathrm{C}$, then the tissue samples were stained with $\mathrm{H} \& \mathrm{E}$ according to the following protocol: Tissue samples were fixed using formalin for $24 \mathrm{~h}$, regularly dehydrated and routinely embedded. The sections were deparaffinized and rehydrated with xylene, $100 \%$ alcohol, 95\% alcohol, 75\% alcohol. The sections were stained in Harris hematoxylin solution at room temperature for $10 \mathrm{~min}$, differentiated with $1 \%$ acid alcohol for 3-5 sec until the nucleus was colored blue, then counterstained in eosin $\mathrm{Y}$ solution for $30 \mathrm{sec}$, dehydrated with 95 then $100 \%$ alcohol, rehydrated with xylene and mounted using neutral balsam. Images were captured using an Olympus BX60 microscope (Olympus Corp., Tokyo, Hapan) using a x40 objective oil immersion lens. Subsequently, the PSCs were analyzed and isolated from the minipig adipose tissues via flow cytometry. Isolation and culture were performed as previously described for hPSC isolation $(14,20)$.

Lipoaspirate specimens were enzymatically digested to obtain the SVF. The SVF was incubated at $37^{\circ} \mathrm{C}$ for $50 \mathrm{~min}$ with antibodies recognizing human PSC antibodies and mp PSC antibodies. Mp PSC antibodies were as follows: CD146-fluorescein isothiocyanate (FITC; 1:100; cat. no. MCA2141F; Bio-Rad Laboratories, Inc., Hercules, CA, USA), CD45-phycoerythrin (PE; 1:100; cat. no. SM563R; OriGene Technologies, Inc., Rockville, MD, USA) and CD34 (1:100; cat. no. ab81289; Abcam, Cambridge, MA, USA). Human PSC antibodies were as follows: CD146-PE (1:100; cat. no. 55305), CD45-FITC (1:100; cat. no. 555482) and CD34-APC (1:100; cat. no. 555824) (BD, Hercules, CA, USA). Cells were sorted using a special order five-laser BD FACS Aria III high-speed cell sorter (BD Biosciences, Franklin Lakes, NJ, USA). Non-viable and hematopoietic cells were excluded based on staining for DAPI and CD45-PE, respectively. $\mathrm{CD} 34^{+} \mathrm{CD} 146{ }^{-}$adventitial cells and $\mathrm{CD} 146^{+} \mathrm{CD} 34$ pericytes were collected as PSCs. The two groups of cells were not clustered clearly, but the fluorescence minus one flow test was used as a control. Samples with detectable pericytes and adventitial populations were examined. Cells were cultured in Gibco Dulbecco's modified Eagle's medium (DMEM; Thermo Fisher Scientific, Inc., Waltham, MA, USA) with Gibco $10 \%$ fetal bovine serum (FBS; Thermo Fisher Scientific, Inc.) and $1 \%$ penicillin/streptomycin. The medium was changed routinely every 3 days. Nine minipig adipose tissue samples were examined and 6 hPSC samples were examined as an interspecies comparison. Prior to analysis, CD $34{ }^{+} \mathrm{CD} 146$ adventitial cells and $\mathrm{CD} 146^{+} \mathrm{CD} 34^{-}$pericytes were purified using FACS and cultured until passages four to six in a monolayer culture.

In vitro osteogenic differentiation assays. For osteogenic differentiation, cells were seeded into 24-well plates at a density of $5 \times 10^{4}$ cells/well. Following attachment, cells were treated with osteogenic differentiation medium (ODM) consisting of DMEM, 10\% FBS, $10 \mathrm{mM} \beta$-glycerophosphate and $50 \mu \mathrm{M}$ ascorbic acid. In select studies, ODM was supplemented with $1 \mu \mathrm{M}$ dexamethasone (Sigma-Aldrich; Merck KGaA, Darmstadt; cat. no. D4902-25MG). The medium was refreshed every three days. After 14 days, osteogenic differentiation was assessed using Alizarin Red S staining according to the manufacturer's protocol (cat. no. 0223; ScienCell Research Laboratories, Inc., San Diego, CA, USA). Briefly, cells were seeded at a density of $5 \times 10^{4}$ cells/well in 24 -well plates. Cells were subsequently fixed for $15 \mathrm{~min}$ at $5^{\circ} \mathrm{C}$ in $4 \%$ paraformaldehyde prior to staining with $2 \%$ Alizarin Red S for $10 \mathrm{~min}$ at room temperature. Cetylpyridinium chloride (10\%; Sigma-Aldrich; Merck KGaA) was subsequently applied for $15 \mathrm{~min}$ at room temperature for quantification. Cells were examined under an inverted fluorescence microscope (magnification, x200) and quantification was performed with a microplate spectrophotometer at $562 \mathrm{~nm}$. 
A
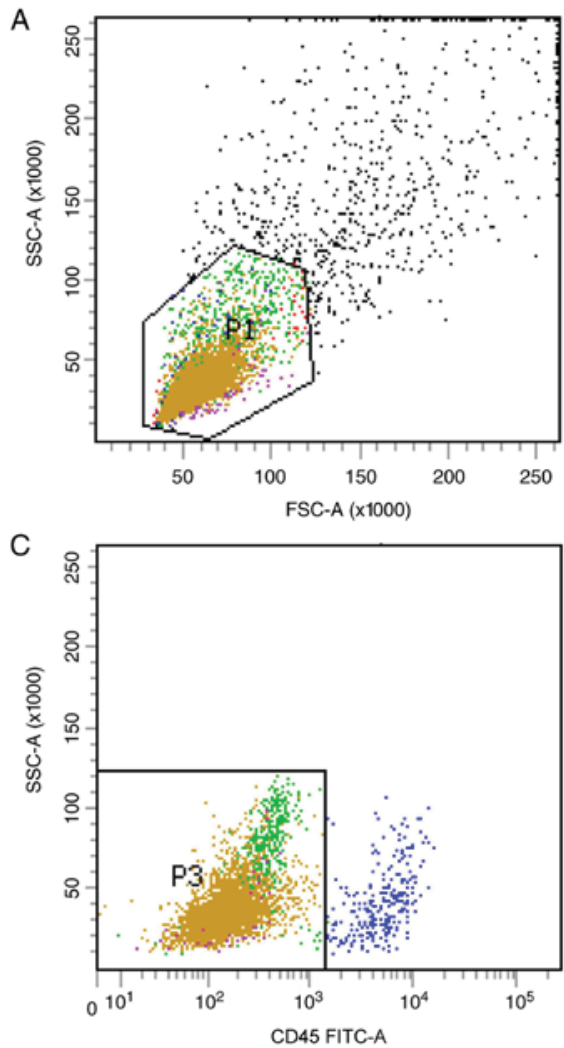

B

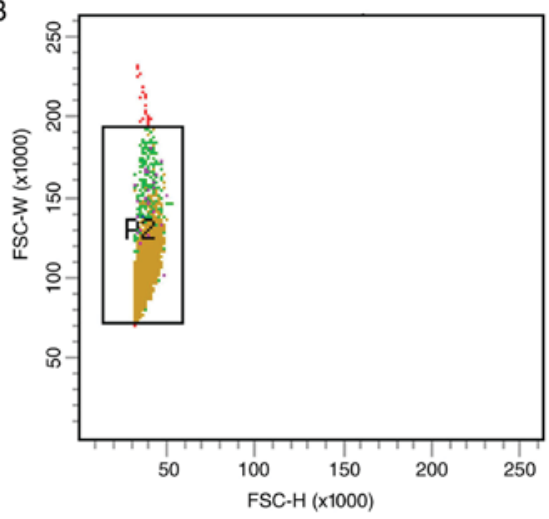

D

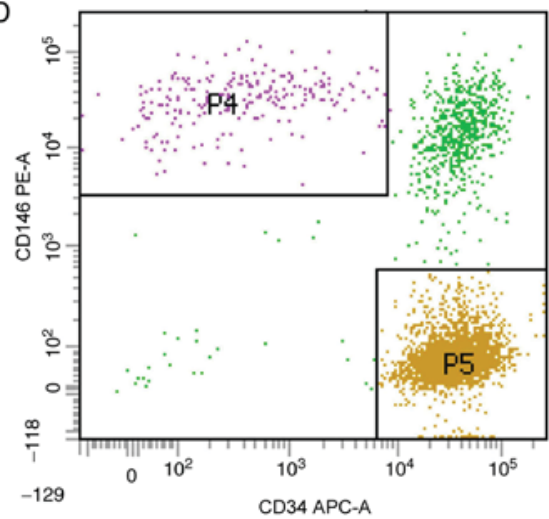

Figure 1. Stromal vascular fraction cell clustering from human liposuction by fluorescence activated cell sorting. (A and B) Viable cells and single cells were identified by their front side detection data through their physical properties. (C) Excluding hematopoietic cells via the expression of CD45. (D) Identification of pericytes and adventitial cells in the CD45- group based on CD34-CD146 ${ }^{+}$and $\mathrm{CD}^{-} 4^{+} \mathrm{CD} 146^{-}$. Different colors indicated different cell populations. P1, red; P2, blue; P3, green. The pink P4 indicates the CD45 ${ }^{-}$D $34{ }^{-} \mathrm{CD} 146^{+}$perithelial cell phenotype; The yellow P5 indicates the $\mathrm{CD}^{-} 5^{-} \mathrm{CD} 34^{+} \mathrm{CD} 146^{-}$adventitial cells phenotype. CD, cluster of differentiation; SSC, side-scattered; FSC, forward-scattered.

In vitro adipogenic differentiation assays. After 14 days of differentiation, the cells were washed gently with phosphate-buffered saline (PBS) and fixed with $4 \%$ paraformaldehyde ( $\mathrm{pH} 7.4$ ) for $10 \mathrm{~min}$. The fixed liquid was discarded. Lipid droplets were stained with $0.5 \%$ Oil Red O in $60 \%$ isopropanol at room temperature for $15 \mathrm{~min}$. The Oil Red $\mathrm{O}$ was removed and the plates were rinsed with water and dried at $37^{\circ} \mathrm{C}$. Subsequently, $60 \%$ isopropanol was used to extract the dye from the cells for 10-20 min, and the cells were washed with PBS twice, at last immersed in PBS and observed under an inverted light microscope (magnification, x200).

$R T-q P C R$. Total RNAs were extracted from the lung tissue samples of each group. cDNA was synthesized using a $\operatorname{TaqMan}^{\mathrm{TM}}$ MicroRNA reverse transcription kit (cat. no. 4366596; Thermo Fisher Scientific,Inc.) and cDNA served as a template for RT-qPCR (Applied Biosystems 7500 Real-Time PCR Instrument; Thermo Fisher Scientific, Inc.). Reactions were conducted in 96 -well optical plates at $95^{\circ} \mathrm{C}$ for $10 \mathrm{~min}$, followed by 40 cycles at $95^{\circ} \mathrm{C}$ for $15 \mathrm{sec}$ and $60^{\circ} \mathrm{C}$ for $1 \mathrm{~min}$. The quantification cycle $(\mathrm{Cq})$ data were determined using default threshold settings (24). The Cc was defined as the fractional cycle number at which the fluorescence passes the fixed threshold. Reactions were run in duplicate to triplicate per RNA isolate. The relative expression of OCN, COL1A1 and PPARG in each group of cells were calculated by RT-qPCR and GAPDH served as an internal standard. Primer sequences were as follows: GAPDH forward, CAATGACCC
CTTCATTGACC and reverse, GAAGATGGTGATGGCCTT TC; COL1A1 forward, GGTTTCAGTGGTTTGGATGG and reverse, TCCATTTTCACCAGGGCTAC; OCN forward, TCA CACTGCTTGCCCTACTG and reverse, CTGCACCTTTGC CAGAATC; and PPARG forward, GCCAAGGATTCATGA CAAGG and reverse, TTGGGCTCCATAAAGTCACC.

Statistical analysis. All results were expressed as means \pm standard error and analyzed using SPSS version 19 (IBM Corp., Armonk, NY, USA). The difference was detected by Student t-test, or one-way analysis of variance followed by Fisher's Least Significant Difference post-hoc test for different group data analysis and $\mathrm{P}<0.05$ was considered to indicate a statistically significant difference.

\section{Results}

mpPSCs and hPSCs are obtained by identical processes. Previous studies have optimized the procedure for obtaining hPSCs (8). In the current study, two subgroups of hPSCs, the CD $45^{-} \mathrm{CD} 34^{-} \mathrm{CD}^{-} 46^{+}$phenotype of perithelial cells (P4) and the $\mathrm{CD}^{-} 5^{-} \mathrm{CD} 34^{+} \mathrm{CD} 146^{-}$phenotype of adventitial cells (P5), were isolated from human liposuction fat by FACS (Fig. 1). Subsequently, this protocol was applied to mp adipose tissue samples. Single cells were gated and histograms of each antibody were compared with the relevant isotype control (Fig. 2). Cells were sorted into CD45-CD34-CD146+ (P4) and $\mathrm{CD}^{-} 5^{-\mathrm{CD}} 34^{+} \mathrm{CD} 146^{-}$cell populations (P5). The two 
A
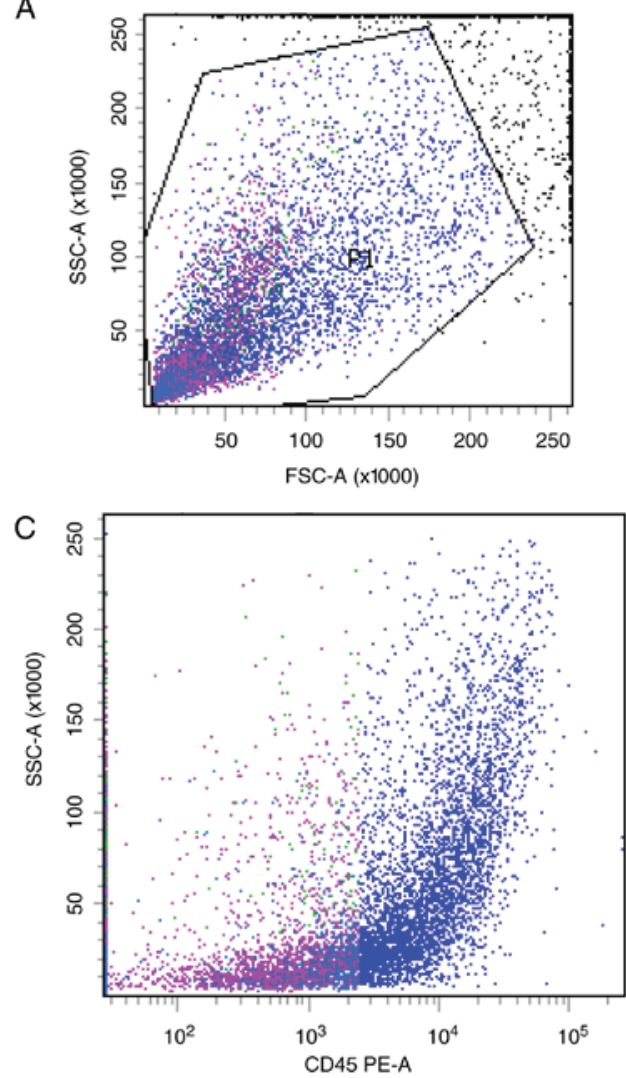
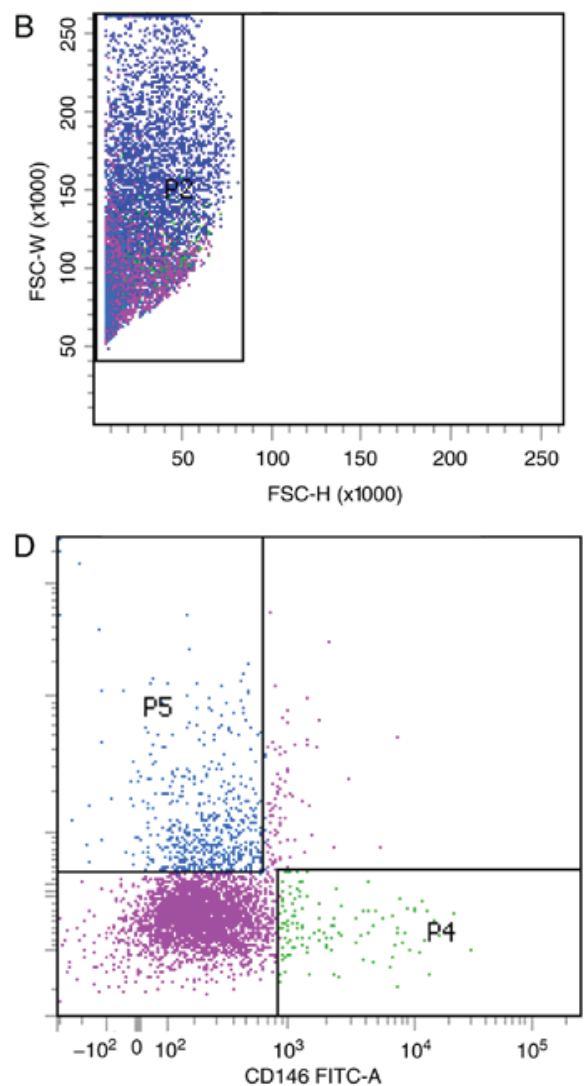

Figure 2. Minipig stromal vascular fraction cell clustering by fluorescence activated cell sorting. (A and B) Viable cells and single cells were identified by their front side detection data through their physical properties. (C) Excluding hematopoietic cells via the expression of CD45. (D) identification of pericytes and adventitial cells in the $\mathrm{CD}_{4} 5^{-}$group based on $\mathrm{CD} 34^{-} \mathrm{CD} 146^{+}$and $\mathrm{CD} 34^{+} \mathrm{CD} 146$. P1, red; P2, blue; P3, pink; P4, green; P5, light blue. CD, cluster of differentiation; SSC, side-scattered; FSC, forward-scattered.
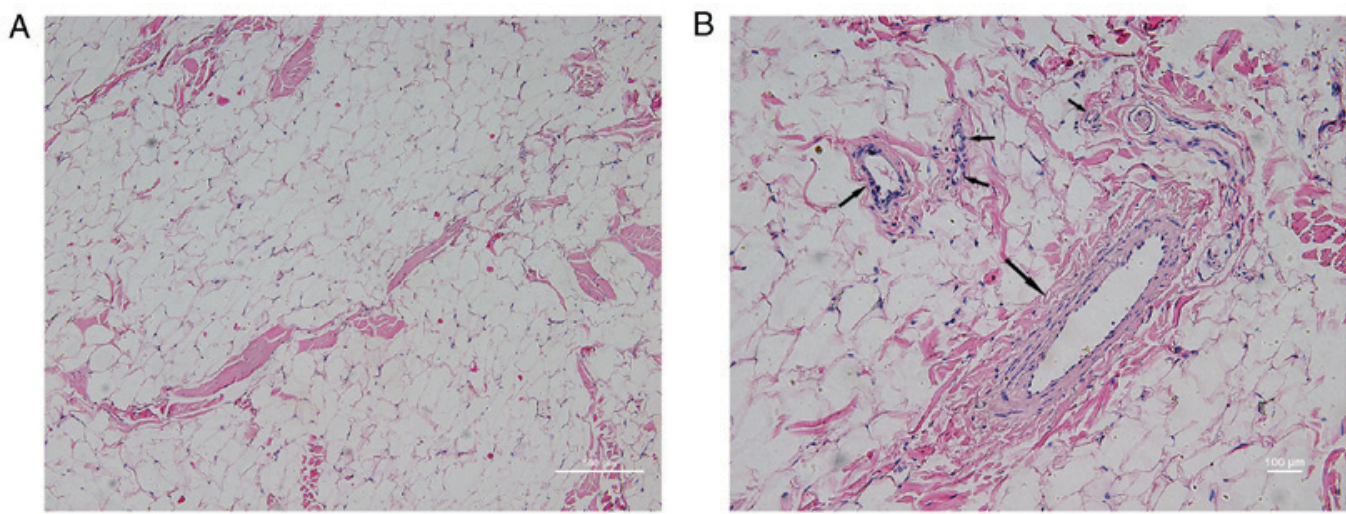

Figure 3. Morphological characteristics of subcutaneous fat from the posterior neck of minipigs by hematoxylin and eosin staining. (A) Low power microscope image (magnification, x10). (B) High-magnification image (magnification, x20). Arrows indicate adipose tissues containing vascular structures.

groups of cells were not clustered clearly, but the fluorescence minus one flow test was used as a loop gate and the results were reliable. $\mathrm{CD} 45^{-} \mathrm{CD} 34^{-} \mathrm{CD} 146^{+}$cell populations and $\mathrm{CD} 45^{-} \mathrm{CD} 34^{+} \mathrm{CD} 146^{-}$cell populations accounted for $1.4 \%$ (P4/P1) and 7.2\% (P5/P1) of SVF cells, respectively, with a total of $8.6 \%$, which was lower than that previously reported in the literature (9). In the current study, immunohistochemistry was not performed; therefore, the hPSC phenotypes of the cells corresponding to that of the mps were used as the supporting evidence to consider these two cell populations as 'PSCs' (mpPSCs).
SVF are abundant in $m p$ white adipose tissue. In order to determine the SVF content in mp adipose tissue, H\&E staining was performed in subcutaneous adipose tissue sampled from the posterior neck of the mps. As shown in Fig. 3, it was observed at low magnification that adipose tissue was predominantly composed of a large number of vacuolar fatty cells and a small quantity of connective tissue. Observation of connective tissue at high magnification demonstrated abundant vascular-like structures, with diameters from several microns to hundreds of microns. The vascular wall exhibited three layers of arteriovenous-like structures (endometrium, intermediate muscle 

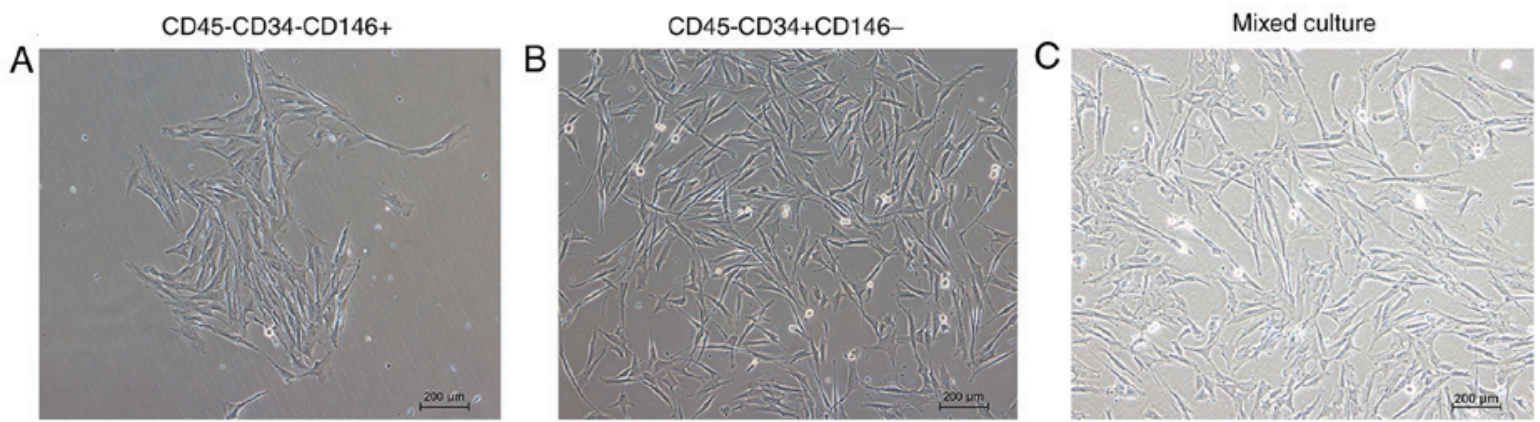

Figure 4. Morphology of sorted minipig cells that adhered to the wall (magnification, $\mathrm{x} 10$ ). The cell morphology of the (A) $\mathrm{CD}^{\circ} 5^{-} \mathrm{CD} 34{ }^{-} \mathrm{CD} 146^{+}$group was longer and narrower, and the cell morphology of the (B) $\mathrm{CD} 45^{-} \mathrm{CD} 34^{+} \mathrm{CD} 146^{-}$group was polygonal. (C) Mixed culture of the two groups of cells. $\mathrm{CD}$, cluster of differentiation.
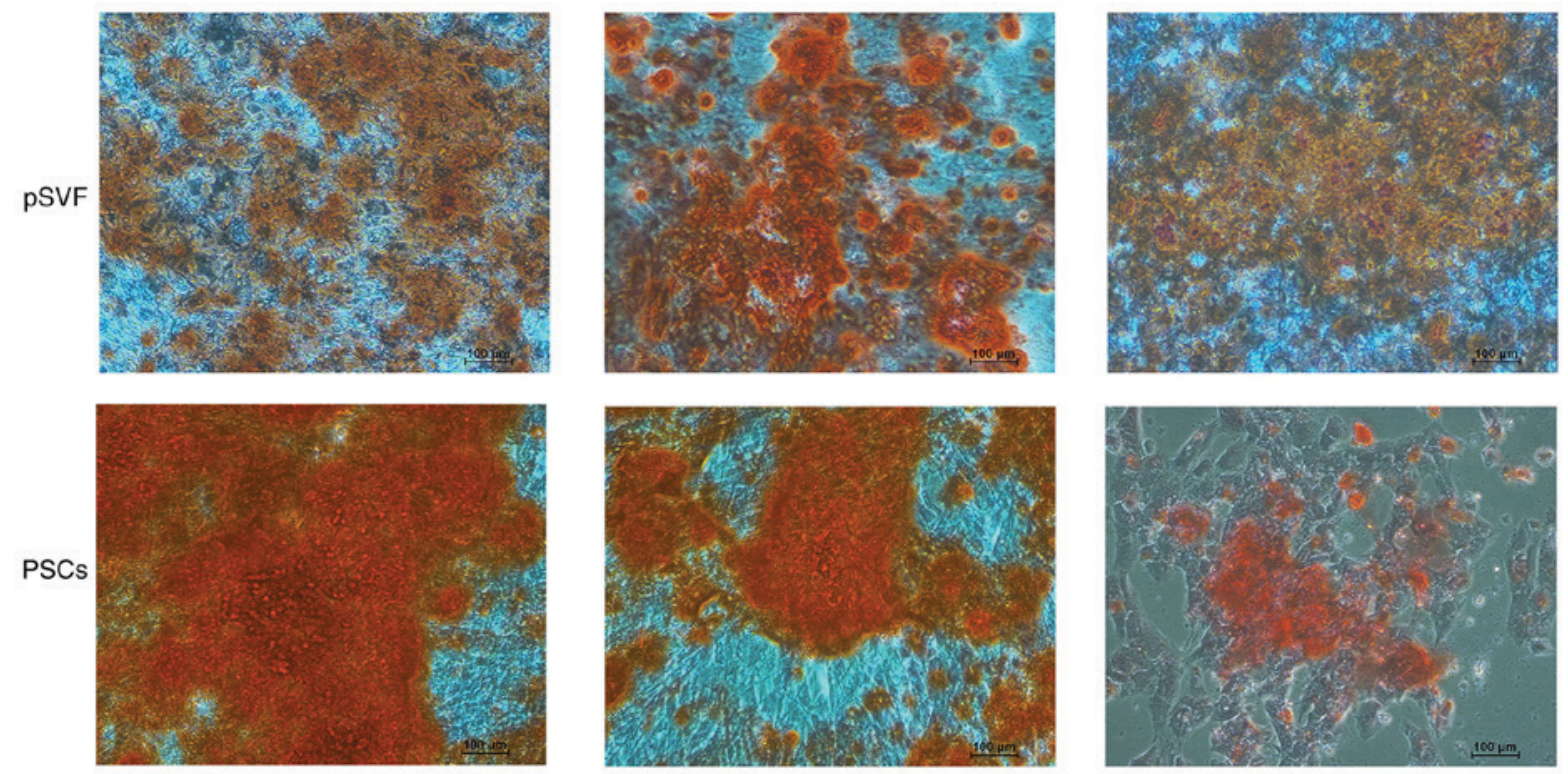

Figure 5. Osteogenic induction differentiation for two weeks, as presented by Alizarin Red staining (magnification, x10). Alizarin Red staining demonstrated typical staining of calcium nodules in the two groups. The staining was much deeper in the group of PSCs with wider area. pSVF, pig stromal vascular fraction; PSCs, perivascular stem cells.

layer and outer membrane) and capillary-like monolayer structures (predominantly including the endothelial layer and the surrounding cells). This region of the structure was termed SVF, and according to the human PSC theory, the fat derived mpPSCs are separate from this region.

Cell morphology of the mpPSCs. The morphology of the cells adhered to the wall are presented in Fig. 4. Following cell sorting, the cells were separated and then mixed in culture. The result indicated that the morphology of the two groups of cells that had adhered to the wall was marginally different. The cell morphology of the CD $45^{-} \mathrm{CD} 34^{-} \mathrm{CD} 146^{+}$group was longer and narrower, and the cell morphology of the $\mathrm{CD} 45^{-} \mathrm{CD} 34^{+} \mathrm{CD} 146$ group was polygonal.

mpPSCs demonstrated MSC characteristics. mpPSCs were evaluated based on their adipogenic and osteoplastic differentiation ability. As presented in Fig. 5, typical staining of calcium nodules was demonstrated by Alizarin Red in the two groups. There was a wider area of deeper staining in the group of PSCs, indicating that mpPSCs had a stronger and more prevalent ability in calcium nodule formation than pSVFs, which indicated that the mpPSCs were able to undergo osteoplastic differentiation.

The ability of adipogenic differentiation was detected by the results of Oil Red O staining (Fig. 6). The results demonstrated the presence of lipid droplets, with grape-like clusters observed in in the two groups. The lipid droplet density of the mpPSCs group was significantly higher than that of the pSVF group, indicating that the lipid composition ability of the mpPSCs was stronger.

Osteogenic induction differentiation and adipogenesis-associated gene expression levels were higher in the mpPSCs group than in the pSVF group. The results of the RT-qPCR (Fig. 7) demonstrate that compared with the pSVF group, the mRNA expression levels of osteogenic induction differentiation regulating genes, $\mathrm{OCN}$ and $\mathrm{COL} 1 \mathrm{~A} 1$, and adipogenesis-associated gene, PPARG in the mpPSCs group were significantly higher $(\mathrm{P}<0.05)$. 

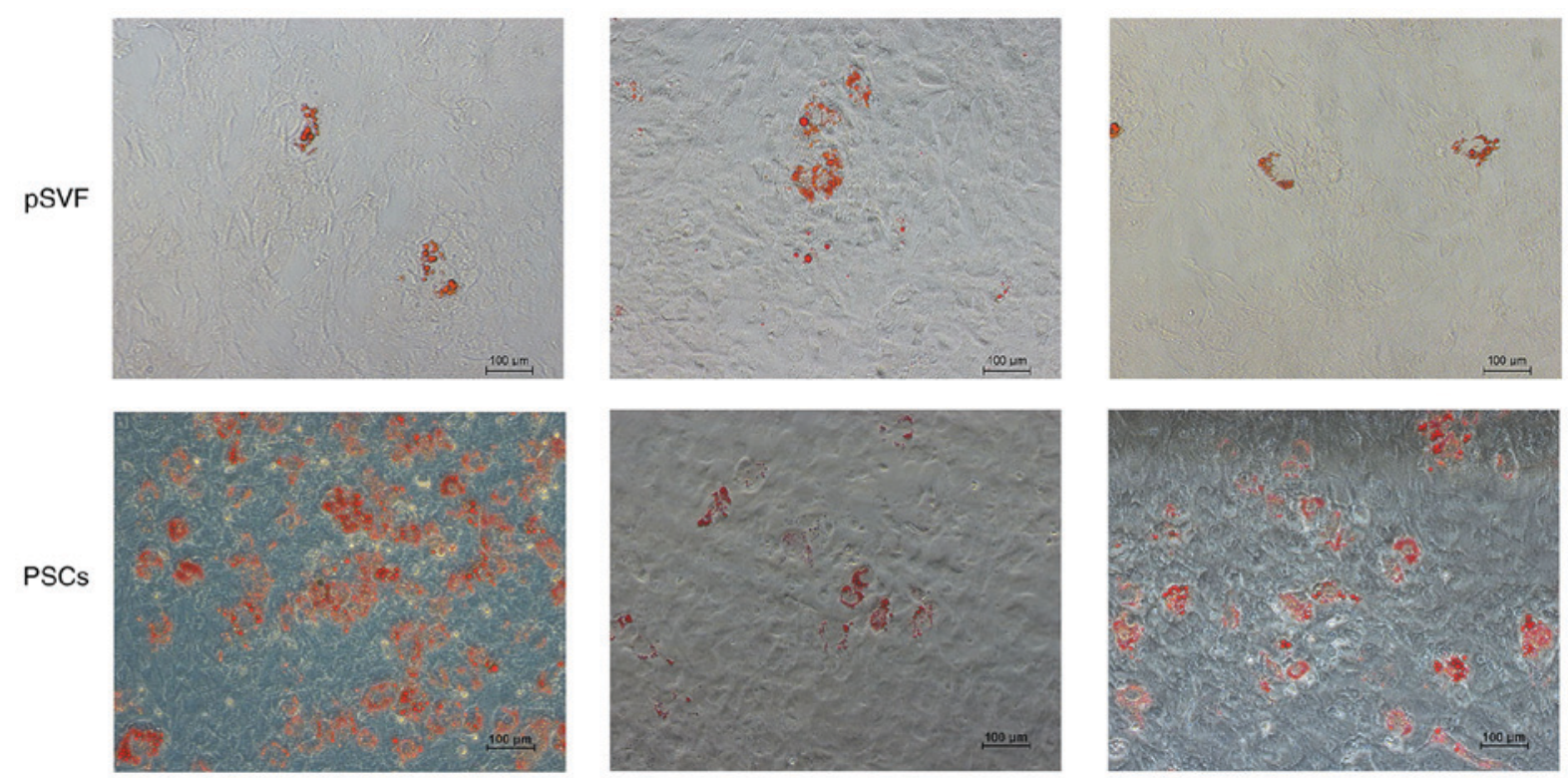

Figure 6. Adipogenic differentiation for two weeks, as presented by Oil Red O staining (magnification, x10). The typical lipid droplets in the two groups were stained with grape bead-like structures. The lipid droplet density of the mpPSCs group was markedly higher than that of the pSVF group. PSCs, perivascular stem cells; pSVF, pig stromal vascular fraction.
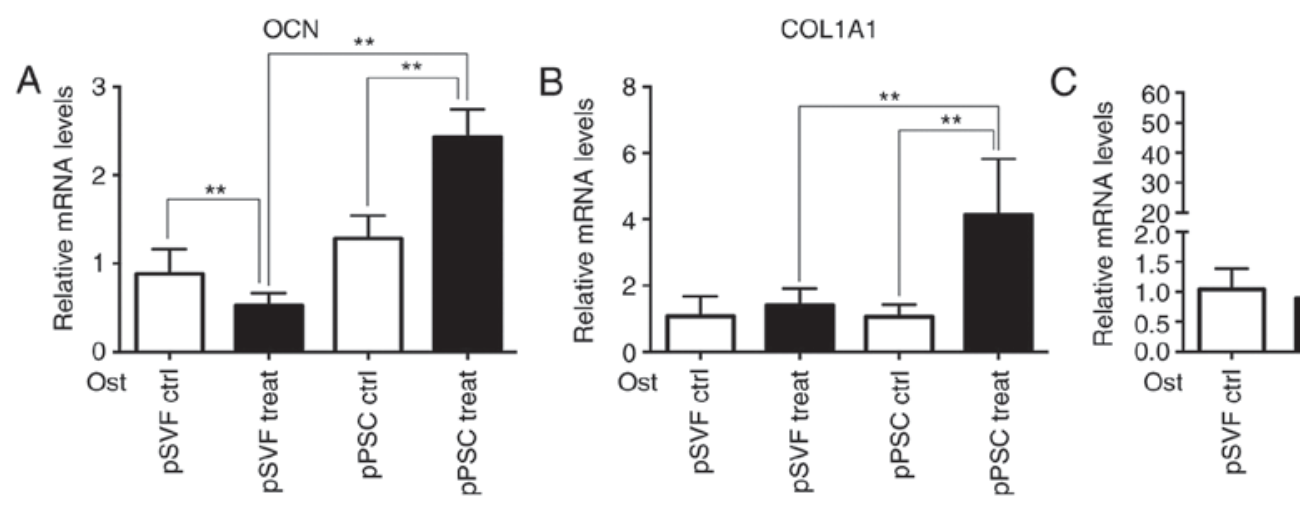

PPARG

Figure 7. Adipogenesis-associated gene expression measured by the reverse transcription-quantitative polymerase chain reaction. The mRNA expression levels of (A) OCN, (B) COL1A1 and (C) PPARG in the pPSC group were significantly higher. ${ }^{* *} \mathrm{P}<0.01,{ }^{* * *} \mathrm{P}<0.001$. OCN, osteocalcin; COL1A1, collagen, type I, $\alpha 1$; PPARG, peroxisome proliferator-activated receptor- $\gamma$; Ctrl, control; pPSCs, pig perivascular stem cells; pSVF, pig stromal vascular fraction; Ost, osteogenic.

\section{Discussion}

The current study investigated mps as a novel source of PSCs for translational effects in bone tissue engineering. The data revealed that mpPSCs could be isolated from SVF with an identical isolation protocol to hPSCs. The present study further confirmed the characteristics of mpPSCs, including the morphology of the cells that adhered to the wall, and their adipogenic and osteoplastic differentiation ability using Alizarin Red and Oil Red O staining, the result demonstrated that mpPSCs exhibited the following characteristics of stem cells: Adherent growth, clonal formation, multipotent differentiation-osteogenesis and adipogenic. Additionally, adipogenesis-associated gene expression was measured using RT-qPCR, and the result demonstrated that compared with the pSVF group, the expression levels of OCN, COL1A1 and PPARG mRNA in the mpPSC group was significantly higher $(\mathrm{P}<0.05)$. The H\&E staining performed in the subcutaneous adipose tissue of the posterior neck of the mps indicated that there was abundant SVF in mps. These data confirm the possibility that mps provide a source of PSCs. The possible novel source of PSCs identified during the current study, which may supplement currently confirmed sources, as described in different species, including humans $(9,10)$, canines (22), sheep (25) and mice (26). Notably, the same markers were used to identify PSCs in these different species, using, in the majority of instances, cross-reactive antibodies. This indicates a highly-conserved set of perivascular markers for an ancestral population of tissue regenerative cells.

Adipose tissue is an attractive source of PSCs, as it is dispensable and accessible with minimal associated morbidity $(27,28)$, PSCs consist of pericytes and adventitial cells; pericytes are a type of cell that typically reside around smaller blood vessels, including capillaries, venules and arterioles, whereas adventitial cells are located around larger arteries and veins $(10,29)$. PSCs have demonstrated osteogenic, chondrogenic, adipogenic, and myogenic potential, indicating the potential for multiple applications in skeletal regenerative 
medicine without culture expansion $(9,11,19,22,27,30)$. mps are a type of easily cultured animal. The observation that CD146 and CD34 have a perivascular location in mp tissues, which coincides with that of established MSC markers is consistent with the characteristic of pericytes and adventitial cells of PSCs described in previous reports $(22,31)$. The current result further confirmed the perivascular location of MSCs in mps, as demonstrated by $\mathrm{H} \& \mathrm{E}$ staining, which has already been described in humans and other animals $(22,25,30,31)$.

The cell can only be defined as PSCs if it satisfies the following conditions: Located in the vascular wall and exhibiting stem cell characteristics $(22,24)$. In humans, there are two types of cell that meet the above-mentioned conditions: CD45 $\mathrm{CD} 34^{-\mathrm{CD}} 146^{+}$phenotype of pericytes and $\mathrm{CD} 45^{-\mathrm{CD}} 34^{+} \mathrm{CD} 146^{-}$phenotype of adventitial cells. However, in the $\mathrm{mp}$ vascular stem cell sorting process, CD $45^{-} \mathrm{CD} 34^{-} \mathrm{CD}^{-} 46^{+}$phenotype and $\mathrm{CD} 45^{-\mathrm{CD}} 34^{+} \mathrm{CD} 146$ phenotype cells were prospectively isolated from SVF from minipigs, and humans had high homology biological background and the same phenotype, and the sorted cells demonstrated the following characteristics of stem cells: Adherent growth, colony formation and multipotential differentiation; however, immunofluorescence was not performed in the present study, which could verify that CD $45^{-} \mathrm{CD} 34^{-} \mathrm{CD} 146^{+}$and $\mathrm{CD}^{-} 5^{-} \mathrm{CD} 34^{+} \mathrm{CD} 146^{-}$are $\mathrm{mp}$ pericyte and adventitial cells, respectively. Thus, in order to evaluate the cross-reactivity of human antibodies with porcine tissue, immunofluorescent detection of markers of pericytes (CD146), adventitial cells (CD34), and endothelium (CD31) should be performed on mp tissue samples in future animal experiments.

In addition, the results of flow cytometry indicated that compared with man, the cell rate of PSC-like cells from mps was lower, due to various potential reasons: Firstly, in the current study, the indirect CD34 antibody marker was used, not the mp antibody, which may have affected the identification of cell surface molecules; additionally, the CD146-FITC antibody used in the present study was a human monoclonal antibody, which worked in the mp tissues, but with less antibody specificity than in human cells; so CD34 and CD146 may not identify adventitial cells and pericytes specifically; finally, blood vessel density in mp fat may be lower than that of human fat. The cell sorting was not obvious in flow cytometry, which also supported the inference of poor antibody specificity. Therefore, it would be prudent to state that the cells involved in the current experiment are termed mp CD45 CD $344^{-} \mathrm{CD} 146^{+}$ and $\mathrm{CD} 45^{-\mathrm{CD}} 34^{+} \mathrm{CD} 146^{-}$progenitors.

In conclusion, the $H \& E$ staining results and the characteristics of stem cells after sorting indirectly support the existence of vascular stem cells in the fat of mps. In vitro experiments demonstrate that the adipogenic differentiation potential of $\mathrm{mp}$ vascular stem cells was significantly stronger than that of non-selected vascular stromal cells. These results lay the foundation for the future isolation and characterization of $\mathrm{CD}_{146^{+}}$and $\mathrm{CD} 34^{+}$cell subpopulations from mp adipose tissues.

\section{Acknowledgements}

Not applicable.

\section{Funding}

The present study was supported by the International Science \& Technology Cooperation Program of China (grant no. 2015DFB30040), the National Science Foundations of China (grant nos. 81300897, 81571815, 81671015, and 81470717) and the Beijing Municipal Natural Science Foundation (grant no. 7152156).

\section{Availability of data and materials}

The datasets used during the present study are available from the corresponding author on reasonable request.

\section{Authors' contributions}

ZC and YZ conceived and designed the study. ZC, CL, NJ, CZ, YW and HG performed the experiments. ZC and $\mathrm{YZ}$ wrote the paper. All authors read and approved the manuscript.

\section{Ethics approval and consent to participate}

All experimental protocols were approved by the Review Board of Peking University (Beijing, China; permit no. LA2014216).

\section{Patient consent for publication}

Not applicable.

\section{Competing interests}

The authors declare that they have no competing interests.

\section{References}

1. de Boer HH: The history of bone grafts. Clin Orthop Relat Res: 292-298, 1988.

2. Kao ST and Scott DD: A review of bone substitutes. Oral Maxillofac Surg Clin North Am 19: 513-521, vi, 2007.

3. Sarkar SK and Lee BT: Hard tissue regeneration using bone substitutes: An update on innovations in materials. Korean J Intern Med 30: 279-293, 2015.

4. Klenerman L: Bone grafts, derivatives and substitutes. Br J Plas Surg 47: 586, 1994.

5. Giannoudis PV, Dinopoulos H and Tsiridis E: Bone substitutes: An update. Injury 36 (Suppl 3): S20-S27, 2005.

6. Sawin PD, Traynelis VC and Menezes AH: A comparative analysis of fusion rates and donor-site morbidity for autogeneic rib and iliac crest bone grafts in posterior cervical fusions. J Neurosurg 88: 255-265, 1998.

7. Frodel JL Jr, Marentette LJ, Quatela VC and Weinstein GS: Calvarial bone graft harvest. Techniques, considerations, and morbidity. Arch Otolaryngol Head Neck Surg 119: 17-23, 1993.

8. Derubeis AR and Cancedda R: Bone marrow stromal cells (BMSCs) in bone engineering: Limitations and recent advances. Ann Biomed Eng 32: 160-165, 2004.

9. Hindle P, Khan N, Biant L and Péault B: The infrapatellar fat pad as a source of perivascular stem cells with increased chondrogenic potential for regenerative medicine. Stem Cells Transl Med 6: 77-87, 2017.

10. Crisan M, Yap S, Casteilla L, Chen CW, Corselli M, Park TS, Andriolo G, Sun B, Zheng B, Zhang L, et al: A perivascular origin for mesenchymal stem cells in multiple human organs. Cell Stem Cell 3: 301-313, 2008.

11. Chung CG, James AW, Asatrian G, Chang L, Nguyen A, Le K, Bayani G, Lee R, Stoker D, Zhang X, et al: Human perivascular stem cell-based bone graft substitute induces rat spinal fusion. Stem Cells Transl Med 3: 1231-1241, 2014. 
12. Lee S, Zhang X, Shen J, James AW, Chung CG, Hardy R, Li C, Girgius C, Zhang Y, Stoker D, et al: Brief report: Human perivascular stem cells and Nel-Like protein-1 synergistically enhance spinal fusion in osteoporotic rats. Stem Cells 33: 3158-3163, 2015.

13. West CC, Hardy WR, Murray IR, James AW, Corselli M, Pang S, Black C, Lobo SE, Sukhija K, Liang P, et al: Prospective purification of perivascular presumptive mesenchymal stem cells from human adipose tissue: Process optimization and cell population metrics across a large cohort of diverse demographics. Stem Cell Res Ther 7: 47, 2016.

14. Nakata M, Nakagomi T, Maeda M, Nakano-Doi A, Momota Y and Matsuyama T: Induction of perivascular neural stem cells and possible contribution to neurogenesis following transient brain ischemia/reperfusion injury. Transl Stroke Res 8: 131-143, 2017.

15. Zhao H, Feng J, Seidel K, Shi S, Klein O, Sharpe P and Chai Y: Secretion of shh by a neurovascular bundle niche supports mesenchymal stem cell homeostasis in the adult mouse incisor. Cell Stem Cell 14: 160-173, 2014.

16. Eliasberg CD, Dar A, Jensen AR, Murray IR, Hardy WR, Kowalski TJ, Garagozlo CA, Natsuhara KM, Khan AZ, Mcbride OJ, et al: Perivascular stem cells diminish muscle atrophy following massive rotator cuff tears in a small animal model. J Bone Joint Surg Am 99: 331-341, 2017.

17. James AW, Zara JN, Corselli M, Chiang M, Yuan W, Nguyen V, Askarinam A, Goyal R, Siu RK, Scott V, et al: Use of human perivascular stem cells for bone regeneration. J Vis Exp: e2952, 2012.

18. James AW, Zara JN, Zhang X, Askarinam A, Goyal R, Chiang M, Yuan W, Chang L, Corselli M, Shen J, et al: Perivascular stem cells: A prospectively purified mesenchymal stem cell population for bone tissue engineering. Stem Cells Transl Med 1: 510-519, 2012.

19. James AW, Zara JN, Corselli M, Askarinam A, Zhou AM, Hourfar A, Nguyen A, Megerdichian S, Asatrian G, Pang S, et al: An abundant perivascular source of stem cells for bone tissue engineering. Stem Cells Transl Med 1: 673-684, 2012.

20. Mcintosh K, Zvonic S, Garrett S, Mitchell JB, Floyd ZE, Hammill L, Kloster A, Di Halvorsen Y, Ting JP, Storms RW, et al: The immunogenicity of human adipose-derived cells: Temporal changes in vitro. Stem Cells 24: 1246-1253, 2006

21. Ruetze M and Richter W: Adipose-derived stromal cells for osteoarticular repair: Trophic function versus stem cell activity. Expert Rev Mol Med 16: e9, 2014.
22. James AW, Zhang X, Crisan M, Hardy WR, Liang P, Meyers CA, Lobo S, Lagishetty V, Childers MK, Asatrian G, et al: Isolation and characterization of canine perivascular stem/stromal cells for bone tissue engineering. PLoS One 12: e0177308, 2017.

23. Fu Y, Liu S, Cui SJ, Kou XX, Wang XD, Liu XM, Sun Y, Wang GN, Liu Y and Zhou YH: Surface chemistry of nanoscale mineralized collagen regulates periodontal ligament stem cell fate. ACS Appl Mater Interfaces 8: 15958-15966, 2016.

24. Livak KJ and Schmittgen TD: Analysis of relative gene expression data using real-time quantitative PCR and the 2(-Delta Delta C(T)) method. Methods 25: 402-408, 2001.

25. Hindle P, Baily J, Khan N, Biant LC, Simpson AH and Péault B: Perivascular mesenchymal stem cells in sheep: Characterisation and autologous transplantation in a model of articular cartilage repair. Stem Cells Dev 25: 1659-1669, 2016.

26. Kang SG, Shinojima N, Hossain A, Gumin J, Yong RL, Colman H, Marini F, Andreeff $M$ and Lang FF: Isolation and perivascular localization of mesenchymal stem cells from mouse brain. Neurosurgery 67: 711-720, 2010

27. Zuk PA, Zhu M, Ashjian P, De Ugarte DA, Huang JI, Mizuno H, Alfonso ZC, Fraser JK, Benhaim P and Hedrick MH: Human adipose tissue as a source of multipotent stem cells. Mol Biol Cell 13: 4279-4295, 2002

28. Frese L, Dijkman PE and Hoerstrup SP: Adipose tissue-derived stem cells in regenerative medicine. Transfus Med Hemother 43: 268-274, 2016.

29. Corselli M, Chen CW, Sun B, Yap S, Rubin JP and Péault B: The tunica adventitia of human arteries and veins as a source of mesenchymal stem cells. Stem Cells Dev 21: 1299-1308, 2012.

30. Askarinam A, James AW, Zara JN, Goyal R, Corselli M, Pan A, Liang P, Chang L, Rackohn T, Stoker D, et al: Human perivascular stem cells show enhanced osteogenesis and vasculogenesis with Nel-like molecule I protein. Tissue Eng Part A 19: 1386-1397, 2013.

31. Esteves CL, Sheldrake TA, Mesquita SP, Pesántez JJ, Menghini T, Dawson L, Péault B and Donadeu FX: Isolation and characterization of equine native MSC populations. Stem Cell Res Ther 8: 80, 2017.

This work is licensed under a Creative Commons Attribution-NonCommercial-NoDerivatives 4.0 International (CC BY-NC-ND 4.0) License. 